the work in this direction, he being thoroughly familiar with the anatomy and biology of the culex and conversant with the technic required; he had already bred numerous varieties in his laboratory at Camp Columbia, and had been sending specimens to Dr. Howard, entomologist, Department of Agriculture, Washington, for aid in identifying the different species. That Dr. Jazear was the member of the board, Dr. Reed being absent in Washington, who produced our first two cases by the bites of mosquitoes, in the persons of Dr. Carroll, who, being an unbeliever, allowed him to apply one mosquito on August 27 , and an American soldier, who was bitten by the same in seet, and three others, Aug. 31, 1900. That Dr. Lazear, not content with this, and not in ignorance, for he had suggested to me what the origin of Carroll's and the soldier's infection was, deliberately allowed himself to be bitten by a mosquito while in one of the wards of the yellow fever hospital (Las Animas) September 13, at $x$ time when Carroll and the soldier were convalescing from their attacks. I am convinced that this mosquito produced the infection which caused his death Sept. 25, 1900.

Major Reed was summoned from Washington and the in vestigation was then undertaken exclusively on the mosquito theory.

These are the facts which I deem necessary to make known for the present.

No one can regret more than I the circumstances which may have led Dr. Finlay to regard the stand taken by the Army yellow fever board as a "tacit denial of his rights to priority"; but his false interpretation of our writings could have never induced me to demean the achievemints of this "grand old man." Neither the Army board, Dr. Carı oll, or anyone can deprive Dr. Finlay of the glory of his discovery. What matters it, and what wonder is it, that he could not impart to the near-sighted all that he knew, when we consider that he lacked the necessary technical training and the material means which were so bountifully placed at our disposal for the demonstration? If he did not indeed convince us at the time that the mosquito was the only means of propagating the disease, are we not convinced of it to-day? And is it not the same mosquito to which he pointed?

Had we followed out his suggestions for clearing the city of yellow fever (New York Medical Record, May 27, 1899), and which were later put into practice with but little variation by Major Gorgas, the date of our liberation from the scourge would have been anticipated by three years.

Dr. Carroll says:

It is too late, after facts have been proved and recorded by others, to claim priority unless one can point to unmistakable evidence in print as proof that the facts have been demonstrated and duly reported.

Aceording to this, Dr. Finlay undoubtedly is entitled to priority; he demonstrated to himself and reported long ago the true facts of a fundamental principle, which the Army board, by its superior advantages, demonstrated more convincingly to the world. Aristides Agramonte, M.D.

\section{The Library of the EI Paso County Medical Society.} Denver, June 1, 1903

To the Editor:- There are but few cities in the United States with a population of less than 25,000 that can boast of a medical library. I was, therefore, agreeably surprised to find one in a recent visit to Colorado Springs. It is housed in a separate alcove in the Corbin Library of the Colorado College. It contains over one thousand books, all arranged in alphabetical order by authors under the following classification: 1, Anatomy; 2, biographies; 3, chemistry; 4 , dentistry ; 5 , gynecology ; 6 , hygiene; 7 , history; 8 , materia medica; 9 , medical diagnosis; 10 , medical jurisprudence; 11 , medicine; 12, miscellaneous; 13 , obstetrics; 14, pathology: 15 , periodicals and reprints; 16 , physiology; 17 , reference books; 18, reports; 19, surgery; 20, veterinary. All medical journals are arranged alphabetically by titles. Reprints are filed in cases under an approximate classification by subjects. A card catalogue arranged by subjects is placed in the alcove, and an author's catalogue is placed in the card catalogue in the general librarian's office. The system of classification adopted by this library is unique in that all the subjects are arranged alphabetically. I find it very admirable for a small library. It looks odd at first to find dentistry flanked by chemistry and gynecology, and physiology between periodicals and reference works, but it certainly has its advantages. Once one knows that everything is arranged alphabetically he can easily find what he wants.

All this was surprising enough, but I noticed a neatly bound pamphlet dangling on a ribbon, across which I read the words, "Catalogue of the Library of the El Paso County Medical Society."

All the work, the arrangement, classification and cataloging was done, not by a hired librarian, but by a committee composed of busy practitioners, Drs. R. K. Hutchings, W. H. Swan, F. L. Dennis and H. W. Hoagland. This committee has done a noble work which the profession of Colorado Springs will come to appreciate more and more as years go by.

The library contains a few old books of interest to the lover of curiosa. John Friend's Emmenologia, 1752; Sydenham's works, 1740, and N. Robinson's "A New Method of Treating Consumption." There will be not a few who will be anxious to find out something about this "new method," now two hundred years old. I will therefore transcribe the full title of the book, which reads as follows:

A new method of treating consumption, wherein all the decays incident to human bodies are mechanically accounted for. With some consideration touching the difference between consumption and other decays that naturally attend old age. To which are added arguments in defense of the possibility of curing ulcers of the lungs; as also reasons for demonstrating that the irregular discharges of all the evacuations in consumption arise from the resistance of the heart not decaying in a simple proportion to the resistance of other parts.

From the title one can gather hints as to the curious con tents of the book. By the way, there is another book by the same Johnson on which I would like to spend a few hours, namely:

A treatise on the virtues of a crust of bread, eat early in a morn ing fast, to which are added some particular remarks concerning the great cures accomplished by the saliva, or fasting spittle as when externally applled, or when internally given, in the scurvy. gravel, stone, rheumatism and diverse other diseases arising from obstruction.

Well, "the virtue of a crust of bread eat early in a morning fast" is an experiment with the effects of which legions are fully acquainted. But of "spittle" applied externally I have heard it used only in eases of violent emergencies and under provoking circumstances. C. D. SpIvak, M.D.

\section{Queries and Minor Notes.}

Anonymous Commenications will not be noticed. Queries for this column must be accompanied by the writer's name and address, but the request of the writer not to pub!ish his name will be faithfully observed.

\section{DO NEGROLS RECOVER FROM PHTHISIS?}

ATLANTA, Ga., June 2, 1903.

To the Editor:- I see in The Jodrnal (May 30 , p. 1520) that Dr. Francis Crosson of New Mexico is desirious of information on
tuberculosis among negroes. After fifteen years of large experience with tuberculosis among the negroes on the farm and in the towns. I can not recall a single case in which treatment made the slightest impression. Not only were all the cases fatal, but the negro succumbs most readily to the infection, and so rapid is the progress of the disease that death soon claims the victim. peculiar hue of the negro's skin is almost an infallible characteristic of the disease. John E. Asherorr.

Ceattanooga, Tenn., June 2, 1903.

To the Editor:-In response to the request of Dr. Crosson of Albuquerque, New Mexico, I observe as follows: From a very extensive professional knowledge of the negro, both in public hospital work and in private practice, and covering a third of a century, have come to the conclusion that the colored race as we meet it in the south, is specially susceptible to the inroads of tuberculosis primarily, and succumbs to this great white plague very rapidy. Indeed, I regard tubereulosis as one among the greatest of the foes of the African under civilization in the United States; and if one of this race ever recovered under my own observation, after contracting consumption, I certainly do not remember it now. With the profession generally in this southern section of our common country, it is a sentiment that when a negro becomes visibly affected with pulmonary phthisis bis doom is already practically sealed. and there is a very short period expected to intervene betweon th 
victim and his taking off as soon as a diagnosis becomes readily appreciable.

E. A. Cobleigit.

Monile, Ala. June 3, 1903.

To the Editor:-Some years ago, while assistant superintendent of the Alabama Insane Hospital at Tuscaloosa, I availed myself of the excellent opportunity there offered of studying the relative frequency and curability of tuberculosis in the white and colored races, from both a clinical and pathologic standpoint. The results of my observations were published in the Nero York Medical Journal, Feb. 23, 1895, and may be epitomized as follows: The mor tality from tuberculosis is greater in the negro race than in the white. The disease runs a more rapidly fatal course in the negro. General miliary tuberculosis is many times more frequent in the negro. Instances of arrest or cure of tubercular disease are com. paratively rare in the negro. Nevertheless, recovery from tuberculosis is not unknown in negroes; I have known two cases.

E. D. Bondurant.

Agricultural Colrege, Miss., June 5, 1903.

To the Editor:-In answer to Francis Crosson's inquiry, I will say that I have known only one case to recover in a practice of 28 years. It is an almost unknown occurrence, and there are many dying in this country from tuberculosis. Tuberculosis with the negro before they were freed was almost unknown. Then they were fed well, clothed well, housed comfortably, made to keep regular hours, and when one was taken sick the very best nursing and medical attention was given him. The kind friends of the negro in the north who are anxious to help him with their money could do him no greater service than to provide a fund to be used in securing him good nursing and first-class medical attention when he is sick. They have one habit that I am not sure they had when slaves, viz., sleeping with their head covered; that adds much to cause this succumbing to tuberculosis. W. H. BARR, M.D.

\section{Marriases.}

B. F. Walker, M.D., Laton, Cal., at Winchester, Ill., May 26. L. MaE James, M.D., to John J. Houton, M.D., both of Detroit, Mich., June 2.

A. C. EckE, M.D., Chicago, to Miss Sadie Beaman of Fond du Lac, Wis., May 31.

Charles EDward Terry, M.D., to Miss Marion Stuart, at Annapolis, Md., May 29.

Fred Crifton Honnold, M.D., Riverside, Ill., to Miss Aimee Coulter of Chicago, June 10.

David M. MCFall, M.D., Mattoon, 1ll., to Miss Fannie Johnson of Quiney, Mass., June 3.

Rowland McFarland, M.D., to Miss Maude Elena La Fergey, both of Daggett, Cal., April 14.

Marion Russell Thomas, M.D., Savannah, Ga., to Miss Ethel Ray Butler of Baltimore, June 9.

Claude Allen Thompson, M.D., to Miss Harriett Pauline Shoenfelt, both of Muskogee, I. T., May 24.

Arthur G. Kessler, M.D., Lyons, Cook County, Ill., to Miss Mary L. Barnum, at Waukegan, Ill., May 20.

\section{Deaths.}

Timothy Barnard Chisholm, M.D. Atlanta (Ga.) Medical College, 1861, acting assistant surgeon in the Confederate service; for many years county physician and coroner; a member of the Medical Association of Georgia and of the Georgia Medical Society of Savannah, died at his home in that city, May 7 , after an illness of three days; aged 63 .

John Newton Dexter Shinkel, M.D. Rush Medical College, Chicago, 1885, a member of the American Medical Association, Mississippi State Medical Association, Mississippi State Board of Health, Tri-State Medical Association; vice-president International Association of Railway Surgeons, 1899-1890; died suddenly at his home in Friar Point, Miss., May 26.

John B. Burdett, M.D. College of Physicians, New York, 1856, for several years president of the Hudson County (N. J.) Medical Society and once president of the Hudson County Pathological Society, died at his home in Jersey City, May 21, from Bright's disease, after an illness of three years, aged 69 .

Andrew Louden . Chapman, M.D. St. Louis Medical College, 1857, died from heart disease, May 15, at his home in Kansas City, Mo., after a long illness, aged 77 . He was at one time the editor and publisher of the Nevo Medical Lra and Sanitarium. He retired from active practice in 1882.
Eliphalet L. Patee, M.D. Starling Medical College, Columbus, Ohio, 1852, surgeon during the Civil War; surgeon-general of Kansas, 1892-1894, member of the Association of Military Surgeons of the United States, died recently at his home in Manhattan, Kan.

Philip H. Keyser, M.D. Chicago Homeopathic Medical College, 1893; Colorado School of Medicine, Boulder, 1902, a member of the American Medical Association, was found dead at his home in Boulder, May 24, aged 31. Autopsy revealed no cause.

William 0. Davies, M.D. captain and assistant surgeon U. S. V., a graduate of the University of Pennsylvania, died at his home in Philadelphia, May 26, after a long illness contracted during his service in the Philippine Islands, aged 36.

Dwight Scott Chamberlain, M.D. New York University, 1862, surgeon during the Civil War, but since 1868 engaged in the law and banking business, died at his home in Lyons, $\mathbf{N}$. Y., May 11, from typhoid fever, after a long illness, aged 64.

Hiram Henry Bingham, M.D. College of Homeopathic Medicine and Surgery of the University of Minnesota, 1896, of Hernan, Minn., died in Minneapolis, May 8, from tuberculosis of the intestines, after an iliness of two years, aged 28 .

Charles F. Hamlin, M.D. Medical School of Maine, Bowdoin College, Brunswick, 1S92, a member of the American Medical Association, died at his home in Medway, Mass., May 16, from pneumonia, after an iliness of two weeks, aged 34 .

Albert N. Robert, M.D. Bellevue Hospital Medical College, New York, 1897, died suddenly from heart disease on the train while returning from his old home in Holyoke, Mass., to his home in Volcano, Cal., May 5, aged 29.

Gustave Boucher, M.D. Royal University of Naples, Italy, 1864, of South Brooklyn, N. Y., died in the Columbus Hospital, Manhattan, May 21, from locomotor ataxia, after an illness of two years, aged 57.

George Osgood Hildreth, M.D. Transylvania University, Lexington, $\mathrm{Ky}$, 1835, the oldest practitioner of Marietta, Ohio, died at his home in that place, May 3, after an illness of four months, aged 90 .

W. M. Willingham, M.D. Atlanta (Ga.) Medical College, 1874, died suddenly, May 12, near his home in Crawford, Ga. He had represented Oglethorpe County for several years in the legislature.

Bernard C. Nunez de Villavicencio, M.D. University of Pennsylvania, Philadeiphia, 1865, formerly of Galveston, Texas, died at his home in New Orleans, May 21, after a brief illness, aged 64 .

Mark T. Loope, M.D. Baltimore Medical College, 1893, surgeon of the Northern Pacific Railway, at Hope, Idaho, died in a hospital at Spokane, Wash., May 22, after a brief illness, aged 46.

John Van Harlingen, M.D. College of Physicians and Surgeons, New York, 1869, died at his home in Brooklyn, N. Y., May 17, from heart disease, after an illness of four months, aged $5 \pi$.

Henry Klemm, M.D. St. Louis College of Physicians and Surgeons, 1882, died at his home in St. Louis, May 24, after an illness of three months, following an attack of influenza, aged 61 .

Nicholas Preifer, M.D. Penn Medical University, Philadelphia, 1863, surgeon during the Civil War, died at his home in Lindenhurst, Long Island, N. Y., May 24, after a long illness, aged 83.

Max J. Reinhold, M.D. Hahnemann Medical College, Philadelphia, 1879, died from hemorrhage of the stomach at his home in Williamsport, Pa., after a long illness, May 12, aged 47.

Thomas H. Mathers, M.D. Medical College of Ohio, Cincinnati, 1883, of LiHovet, $B$. $\triangle$., died from septicemia following frozen feet, at New Westminster, B.C., April 16, aged 45.

Samuel S. Scott, M.D. Medical College of Ohio, Cincinnati, 1854, a surgeon in the Confederate service during the Civil War, died at his home in Erlanger, Ky., May 22, aged 77.

Waller Overton Bullock, M.D. Bellevue Hospital Medical College, 1869, died at his home in Lexington, Ky., May 18, from paralysis, after an invalidism of four years, aged 61 .

Joseph B. Cutts, M.D. Medical School of Maine, Bowdoin College, Brunswick, 1842, an early settler of Polo, Ill., died at the home of his son in St. Louis, May 18, aged 83.

Thomas B. Ennor, M.D. State University of Iowa, Iowa City, 1888, of Potosi, Wis., died at Phoenix, Ariz., April 27, from tuberculosis, after an illness of one year, aged 40 . 